\title{
Lung Carcinoma Metastatic in the Bone
}

National Cancer Institute

\section{Source}

National Cancer Institute. Lung Carcinoma Metastatic in the Bone. NCI Thesaurus. Code C36305.

A carcinoma that arises from the lung and has metastasized to the bone. 